\title{
Formação e educação da mulher e o caderno de Economia Doméstica (Dourados, Mato Grosso - 1972)
}

\author{
Women's education and training and the Domestic
} Economy notebook (Dourados, Mato Grosso - 1972)

Formación y educación de la mujer e cuaderno de Economía Doméstica (Dourados, Mato Grosso - 1972)

\author{
INÊS VELTER MARQUES (iDa
}

AlESSANDRA CRISTINA FURTADO (iD ${ }^{\mathrm{b}}$

\section{Resumo}

Este artigo insere-se nas abordagens sobre a história das instituições escolares, com um estudo direcionado para as práticas de formação e educação das mulheres, cuja finalidade é contribuir para a compreensão da seguinte problemática: como a disciplina de Economia Doméstica foi tratada em um caderno de uma ex-aluna da turma do Curso do Ginasial do Colégio Estadual Presidente Vargas, localizado na cidade de Dourados, interior do estado de Mato Grosso, no início dos anos de 1970? Assim, este artigo busca analisar o ensino de Economia Doméstica no Colégio Estadual Presidente Vargas da cidade de Dourados, tomando como fonte principal de pesquisa um caderno de uma ex-aluna do Curso Ginasial do ano de 1972. A pesquisa desenvolveu-se a partir das referências ligadas à história, à história da educação, à história das mulheres, à história da educação da mulher e ao currículo, bem como, com base em fontes documentais. A partir dos registros apresentados pela ex-aluna do Curso Ginasial no caderno foi possível entrever parte do processo de ensino da disciplina de

\footnotetext{
a Universidade Federal da Grande Dourados (UFGD), Dourados, MS, Brasil. Mestre em Educação, e-mail: ines.velter@gmail.com

b Universidade Federal da Grande Dourados (UFGD), Dourados, MS, Brasil. Doutora em Educação, e-mail: alessandrafurtado@ufgd.edu.br
} 
Economia Doméstica, bem como compreender os conteúdos trabalhados e desenvolvidos para a formação e a educação das mulheres moradoras do interior do estado de Mato Grosso. Contudo, o caderno enquanto fonte documental revelou que a disciplina de Economia Doméstica mediante os seus conteúdos visava à formação e à educação das jovens como boas donas de casa, mulheres prendadas em seus afazeres domésticos, boas mães de família e, além disso, boas administradoras financeiras de seus lares.

Palavras-chave: Caderno Escolar. Disciplina de Economia Doméstica. História de Instituição Escolar. Cultura Escolar. Mulher.

\section{Abstract}

This article is part of the approaches on the history of school institutions, with a study directed to the training and education practices of women, whose purpose is to contribute to the understanding of the following problem: how was the discipline of Home Economics treated in a notebook of a former student of the Junior High School class at Colégio Estadual Presidente Vargas, located in the city of Dourados, in the state of Mato Grosso, in the early 1970s? Thus, this article seeks to analyze the teaching of Home Economics at Colégio Estadual Presidente Vargas in the city of Dourados, taking as a main source of research a notebook of a former student of the Ginasial Course of the year 1972. The research was developed from the references linked to history, the history of education, the history of women, the history of women's education and the curriculum, as well as based on documentary sources. From the records presented by the former student of the Ginasial Course in the notebook, it was possible to glimpse at part of the teaching process of the discipline of Home Economics, as well as to understand the contents worked and developed for the training and education of women living in the interior of the state of Mato Grosso. However, the notebook as a documentary source revealed that the discipline of Home Economics through its contents aimed at the training and education of young women, as good housewives, women trapped in their domestic chores, good family mothers and, in addition, good financial administrators of their homes.

Keywords: School notebook. Home Economics Discipline. History of School Institution. School Culture. Woman.

\section{Resumen}

Este artículo se inserta em los enfoques sobre la historia de las instituciones escolares, con un estudio dirigido a las prácticas de formación y educación de las mujeres, cuya finalidad es contribuir para la comprensión de la siguiente problemática: ¿Cómo se trató la materia de Economía Doméstica en un cuaderno de una ex alumna de la clase de enseñanza secundaria del Colegio Estatal Presidente Vargas, ubicado en la ciudad de Dourados, interior del estado de Mato Grosso, a principios de los años de 1970? Así, 
este artículo busca analizar la enseñanza de Economía Doméstica en el Colegio Estatal Presidente Vargas de la ciudad de Dourados, tomando como principal fuente de investigación un cuaderno de una ex alumna de la clase de enseñanza secundaria del año 1972. La investigación se desarrolló a partir de las referencias vinculadas a la historia, a la historia de la educación, a la historia de la mujer, a la historia de la educación de la mujer y el currículo, así como con base en fuentes documentales. A partir de los registros presentados por la ex alumna de la clase de enseñanza secundaria, en el cuaderno se pudo vislumbrar parte del proceso de enseñanza de la materia de Economía Doméstica, bien como comprender los contenidos trabajados y desarrollados para la formación y educación de las mujeres residentes en el interior del estado de Mato Grosso. Con todo, el cuaderno como fuente documental reveló que la materia de Economía Doméstica a través de sus contenidos apuntaba a la formación y a la educación de las jóvenes como buenas amas de casa, mujeres dotadas en sus quehaceres domésticos, buenas madres de familia y, además, buenas administradoras financieras de sus hogares.

Palabras clave: Cuaderno escolar. Disciplina de Economía Doméstica. Historia de la Institución Escolar. Cultura escolar. Mujer.

\section{Introdução}

As pesquisas em História da Educação anteriores à década de 1990 privilegiavam as políticas públicas e a evolução das ideias pedagógicas. Para Lopes e Galvão (2001, p. 30), muitas dessas investigações "tinham como principais objetos as mudanças ocorridas sucessivamente nos sistemas de ensino na perspectiva da ação do Estado, de um lado, e o pensamento pedagógico, de outro”. No entendimento dessas autoras, essas pesquisas acabavam por tratar de um passado educacional que expressava um desejo, mas não uma realidade ou aspecto dela. Assim, poucos pesquisadores tratavam de assuntos relativos às instituições escolares, das práticas escolares, dos alunos e dos professores.

Mas, com as mudanças ocorridas na pesquisa em História da Educação a partir dos anos de 1990, influenciadas pelas correntes historiográficas oriundas da Escola Francesa, principalmente pela Nova História Cultural, possibilitou-se que pesquisadores desta área passassem a se dedicar a outra proposta de estudo, isto é, uma proposta voltada a um pluralismo epistemológico e temático. Com isto, novos objetos e temas, bem como novos problemas e procedimentos de análise, integraram-se à pesquisa em História da Educação, favorecendo outros caminhos para o seu estudo. 
O interesse pelas instituições escolares e pelo seu fazer cotidiano, em uma perspectiva histórica, acabou por lançar novos olhares aos objetos da escola. E o caderno escolar se tornou um desses objetos de interesse de investigação, como esclarece Viñao Frago (2008, p. 16). Segundo o autor, os cadernos permaneceram, até “a década de 1980”, esquecidos em um canto qualquer.

Ainda que os cadernos tenham permanecido à sombra, esquecidos no fundo de gavetas, armários e/ou caixas até aproximadamente a década de 1980, Mignot (2010, p. 425), analisando a produção historiográfica em educação mais recente, assinalou que o interesse por esse objeto-memória advém de um contexto "marcado por um 'giro memorialístico' que se caracteriza pela valorização da memória individual e coletiva, como uma reação ao "presentismo"'.

O artigo ora proposto incide em analisar o ensino da disciplina de Economia Doméstica, no Colégio Estadual Presidente Vargas, da cidade de Dourados, tomando como fonte principal de pesquisa um caderno de uma ex-aluna do Curso Ginasial, do ano de 1972. Para tanto, buscamos analisar e contribuir para a compreensão da seguinte problemática: como a disciplina de Economia Doméstica foi tratada em um Caderno de uma ex-aluna do Curso Ginasial do Colégio Estadual Presidente Vargas, localizado na cidade de Dourados, interior do estado do Mato Grosso, do início dos anos de 1970.

A delimitação do recorte temporal desta pesquisa se justifica em razão de o Caderno da ex-aluna do Curso Ginasial, tomado como fonte principal do estudo, ter sido escrito e resultante da disciplina de Economia Doméstica, ministrada no ano de 1972.

Os cadernos escolares, segundo Viñao Frago (2008, p. 15), “são fontes não menos complexas que outras, as quais, nas últimas décadas, figuram no cruzamento de três campos historiográficos relacionados e complementares: a História da Infância, a História da Cultura Escrita e a História da Educação". O autor ainda assinala que os cadernos escolares são fontes de pesquisa para a investigação do ensino, da aprendizagem e da propagação da cultura escrita. Estes materiais/documentos são aptos para oferecer informações sobre a realidade escolar e as atividades efetuadas na escola (VIÑAO FRAGO, 2008). Assim, podemos entender que os cadernos constituem parte importante e fundamental da cultura escolar. 
A esse respeito, Gvirtz e Larrondo (2008, p. 39) esclarecem que é possível compreender o caderno como produto da cultura escolar pelo fato de este pertencer a uma instituição específica, na qual atua como dispositivo, transformando saberes, valores ou ideologias em "outra coisa".

Para desenvolver este artigo, além do Caderno da disciplina de Economia Doméstica da ex-aluna do Curso Ginasial, foi necessário recorrermos também a outras fontes, tais como: fotografias, jornais, entre outros. Utilizamos ainda as referências ligadas à história, à história da educação, à história das mulheres, à história da educação da mulher e ao currículo.

Este texto se organiza em três seções que se complementam. Na primeira, apresentamos a história da instituição escolar Colégio Presidente Vargas, da cidade de Dourados, no qual a aluna egressa do Curso Ginasial estudou. Na segunda seção, percorremos os vestígios da composição curricular do Curso Ginasial do Colégio Estadual Presidente Vargas, bem como, focalizamos a disciplina de Economia Doméstica. E, por fim, na terceira seção, buscamos analisar as práticas de formação e educação das mulheres, presentes no Caderno da disciplina de Economia Doméstica da ex-aluna do Curso Ginasial, de Dourados.

\section{História da instituição escolar onde a ex-aluna do Curso Ginasial estudava: o Colégio Estadual Presidente Vargas de Dourados}

O primeiro Ginásio público foi criado em Dourados, no dia 02 de outubro de 1951, por meio da Lei $\mathrm{n}^{\circ}$ 427, do mesmo ano, pelo governador do estado de Mato Grosso, o Dr. Fernando Corrêa da Costa, sob a denominação de Ginásio Estadual Presidente Vargas. Todavia, há de se destacar que esse Ginásio começou a funcionar na cidade somente no ano de 1958. Em sua criação e implantação esteve envolvido um grupo de políticos sul-mato-grossenses, liderado pelo vereador Celso Muller do Amaral, que esteve por várias vezes em Cuiabá, buscando viabilizar junto aos políticos da capital o funcionamento desse Ginásio. Amaral foi um político que lutou pelas questões educacionais, inclusive, foi ele quem articulou, juntamente com 
o professor José Pereira Lins, a implantação do Primeiro Ginásio particular em Dourados, como uma extensão do Ginásio Osvaldo Cruz, de Campo Grande (MARQUES, 2014).

A euforia criada em torno do funcionamento do Ginásio Estadual Presidente Vargas repercutiu em Dourados e na região, sendo destaque em matérias dos jornais que circulavam na década de 1950. O Jornal O Progresso, por exemplo, publicou a seguinte manchete, em $1^{\circ}$ de dezembro de 1957, na primeira página: “[...] a quase conclusão do prédio, onde irá funcionar a escola, gera grande expectativa em torno desta instituição por parte da população [...]". Outra edição deste mesmo Jornal, que circulou um ano depois, mais precisamente em 1958, escreveu:

A inauguração das aulas do Ginásio Estadual Presidente Vargas, ocorrida segunda feira última, representou inegavelmente uma bela demonstração do civismo, da cultura e da verdadeira fraternidade que já se criou em torno desse novo estabelecimento de ensino. Em presença das numerosas autoridades e professores presentes, foi inicialmente entoado o Hino Nacional, pela centena de alunos formada, no pátio do ginásio. O Dr. Celso Muller do Amaral, Diretor do estabelecimento fez brilhante e substancioso alocução aos alunos, destacando a importância da verdadeira educação. Falou, em seguida, o Dr. Raul Bezerra, um dos integrantes do corpo docente cujas palavras foram recebidas com gerais aplausos. Falaram ainda Dr. Weimar Torres congratulando-se com os presentes e com a cidade por aquele acontecimento e o Sr. Walmor Borges, em nome dos professores e alunos do Ginásio Osvaldo Cruz, manifestando satisfação pelo acontecimento. Finalmente foi procedida a benção do prédio pelo Reverendo pároco Frei Teodardo e tomada uma fotografia para registro do importante e significativo acontecimento (JORNAL O PROGRESSO, 1958, p. 2).

$\mathrm{Na}$ inauguração das aulas no Ginásio Presidente Vargas estiveram presentes lideranças políticas, proprietários de jornais, membros do corpo docente, professores de outras instituições de ensino de Dourados e o pároco local. Entre os políticos, estavam os vereadores Dr. Celso Muller do Amaral e Dr. Weimar Torres. Celso Muller do Amaral, além de político local, também se tornou professor e primeiro diretor do Ginásio (MARQUES, 2014).

A partir do movimento que envolveu a criação e a instalação do Ginásio Presidente Vargas em Dourados nos anos de 1950 torna-se necessário compreender alguns aspectos que marcaram a história do ensino secundário no Brasil e, em particular, no estado de Mato Grosso, nas décadas de 1940 e 1950. De acordo com Souza (2008, p. 186), a Reforma Capanema acelerou a expansão desse ramo de 
ensino médio nas décadas de 1940, no Brasil, possibilitando "[...] a consolidação de um imaginário de excelência escolar cultivado nos ginásios e colégios, especialmente nos estabelecimentos públicos, compartilhado por gerações de brasileiros que tivessem ou não passado pela escola secundária [...]”. Entre as principais características que marcaram a expansão do ensino secundário no período, “[...] estavam, de um lado, um acentuado crescimento horizontal, no número de estabelecimentos e, de outro, um significativo crescimento vertical de ampliação de matrícula por estabelecimentos [...]" (SILVA, 1957, p. 182).

Em Mato Grosso, no mesmo período da criação do Ginásio Presidente Vargas, na primeira metade da década de 1950, o ensino secundário no Estado passava por um processo de expansão, com a criação de novas instituições de ensino secundárias, fora do eixo das cidades principais, na época constituído pela capital Cuiabá e pelas cidades de Campo Grande e Corumbá. Assim, podemos dizer que esse Ginásio Estadual em Dourados - criado em 1951, mas instalado e posto em funcionamento em 1958 - ocorreu em um período de expansão tanto do ensino secundário no Brasil quanto em Mato Grosso.

O Ginásio Estadual Presidente Vargas, desde a sua implantação, representou a efetivação prática e objetiva das aspirações e dos valores mais elevados da época, no que se refere ao ensino, uma vez que tinha um elevado prestígio intelectual perante a sociedade de Dourados e região. Em sua trajetória histórica, esse Ginásio conquistou novos cursos, o que resultou em um aumento significativo do número das matrículas. Nesse percurso, a instituição acompanhou as mudanças que ocorriam no âmbito estadual e nacional (MARQUES, 2014).

Ao iniciar suas atividades em 1958, o Ginásio Estadual Presidente Vargas oferecia apenas o Curso Ginasial de primeiro ciclo, com quatro anos de duração, conforme prescrito pela Lei Orgânica no 4.244 de 9 de abril de 1942. Esses ginásios que ofereciam o primeiro ciclo também passaram a ofertar o segundo ciclo, que se dividia em clássico e científico.

Em 1963, o Ginásio passou a ser denominado Colégio Estadual Presidente Vargas e a atender também a uma clientela interessada em prosseguir os estudos no segundo ciclo do ensino médio. Inicialmente, o Curso Científico funcionou com as 
aulas ministradas em uma sala na Associação Comercial e Empresarial de Dourados (ACED), pois, como registram as Atas do Colégio, no período não havia sala disponível para essa turma no estabelecimento.

O Colégio permaneceu como a única instituição pública de ensino secundário em Dourados até quase o final dos anos de 1960, quando, então, foram instalados os cursos ginasiais na Escola Pública Abigail Borralho e na Escola Dom Bosco - em Indápolis, distrito de Dourados. Ainda que fosse característica comum às instituições de ensino secundário ofertar o ensino normal, o Colégio Estadual Presidente Vargas nunca ofereceu essa modalidade, pois ela foi implantada em Dourados pelo poder público somente na década de 1970, com a instalação do curso de formação de professores primários, no Centro Educacional de Dourados (atual Escola Estadual Menodora Fialho de Figueiredo).

A partir da implantação da Reforma de Lei no 5.692/1971, o Colégio passou a ter uma nova denominação, uma vez que oferecia as duas modalidades de ensino, o primeiro e segundo graus. Tal circunstância fez com que, a partir do Decreto $\mathrm{n}^{\mathrm{o}}$ 2.086 de 08 de julho de 1974, artigo 42, item III da Constituição Estadual, fosse decretada a criação, no município de Dourados, publicada no Diário Oficial do Estado de Mato Grosso em 10 de julho de 1974, da Escola Estadual de $1^{\circ}$ e $2^{\circ}$ Graus Presidente Vargas - nomenclatura que se manteve até o ano de 1996, quando houve nova redistribuição da rede escolar. A partir de então, e até os dias atuais, a instituição é denominada Escola Estadual Presidente Vargas, a qual atende alunos do Ensino Fundamental e do Ensino Médio da cidade e região (MARQUES, 2014).

\section{Vestígios da Composição Curricular do Curso Ginasial: o caso da disciplina de Economia Doméstica}

O currículo é uma categoria importante para análise da história das instituições escolares, pois possibilita identificar tanto os processos de homogeneização da educação institucionalizada de um modo geral, como a realidade interna dos processos desta escolarização. No entendimento de Goodson (1997, p. 20), "o currículo escrito proporciona-nos um testemunho, uma fonte documental, 
um mapa variável do terreno: é também um dos melhores roteiros oficiais para a estrutura institucionalizada da educação”. O currículo oferece pistas para identificar as relações entre a escola e a sociedade, "porque mostra como escolas tanto refletem como refratam definições da sociedade sobre conhecimento culturalmente válido em formas que desafiam os modelos simplistas da teoria da reprodução" (GOODSON, 1995, p. 118).

Nessas circunstâncias, cabe compreender a composição curricular do Curso Ginasial no Presidente Vargas, no qual a disciplina de Economia Doméstica foi inserida. A primeira Lei de Diretrizes e Bases da Educação Nacional, a de $\mathrm{n}^{\mathrm{o}}$ 4.024/61, no que se refere ao ensino secundário, não trouxe alterações estruturais, pois permaneceu o ginásio com quatro anos de duração e o colegial com três anos. Porém, no que diz respeito ao currículo do ensino secundário, este foi organizado em disciplinas obrigatórias e complementares, de caráter optativo, conforme prevê o artigo 35, da LDB de 1961:

Ao Conselho Federal de Educação compete indicar, para todos os sistemas de ensino médio, até cinco disciplinas obrigatórias, cabendo aos conselhos estaduais de educação completar o seu número e relacionar as de caráter optativo que podem ser adotadas pelos estabelecimentos de ensino (BRASIL, 1961).

Essa Lei institui a flexibilização curricular por meio da atribuição de competências compartilhadas para determinação das disciplinas obrigatórias e optativas entre o Conselho Federal da Educação (CFE), os Conselhos Estaduais e os estabelecimentos de ensino. Para o ensino secundário, as diretrizes curriculares indicavam:

Art. 44. O ensino secundário admite variedade de currículos, segundo as matérias optativas que forem preferidas pelos estabelecimentos.

$\S 1^{\circ} \mathrm{O}$ ciclo ginasial terá a duração de quatro séries anuais e o colegial, de três no mínimo.

$\S 2^{\circ}$ Entre as disciplinas e práticas educativas de caráter optativo no $1^{\circ}$ e $2^{\circ}$ ciclos, será incluída uma vocacional, dentro das necessidades e possibilidades locais.

Art. 45. No ciclo ginasial serão ministradas nove disciplinas. Parágrafo único. Além das práticas educativas, não poderão ser ministradas menos de 5 nem mais de 7 disciplinas em cada série, das quais uma ou duas devem ser optativas e de livre escolha do estabelecimento para cada curso.

Art. 46. Nas duas primeiras séries do ciclo colegial, além das práticas educativas, serão ensinadas oito disciplinas, das quais uma ou duas optativas, de livre escolha pelo estabelecimento, sendo no mínimo cinco e no máximo sete em cada série. 
$\S 1^{\circ}$ A terceira série do ciclo colegial será organizada com currículo aspectos linguísticos, históricos e literários.

$\S 2^{\circ}$ A terceira série do ciclo colegial será organizada com currículo diversificado, que vise ao preparo dos alunos para os cursos superiores e compreenderá, no mínimo, quatro e, no máximo, seis disciplinas, podendo ser ministrada em colégios universitários (BRASIL, 1961, p. 75).

Relativamente à opção da Língua Estrangeira, os Conselhos Estaduais de Educação seriam os responsáveis pela decisão. Mesmo assim, as escolas acabaram por seguir as sugestões do Conselho Federal de Educação, em parte, por falta de professores capacitados em disciplinas diferenciadas (ZOTTI, 2004). Para esse autor, juntamente com essas transformações, houve uma adaptação do ensino secundário ao quadro econômico brasileiro, coexistindo, de um lado, uma formação humanística propedêutica e, de outro, uma científica, mais ajustada à realidade econômico-industrial do país.

No Ginásio Presidente Vargas, no início do ano letivo de 1962, realizou-se a primeira reunião da congregação, com o objetivo de estudar um plano provisório de organização curricular nos moldes da Lei das Diretrizes e Bases da Educação Nacional de 1961. Nesse mesmo ano, a grade curricular do Curso Ginasial já funcionou com algumas alterações prescritas pela Lei, como mostra o Quadro 1:

Quadro 1 - Grade Curricular do Curso Ginasial do Presidente Vargas de Dourados, do período de 1962

\begin{tabular}{|l|l|l|l|l|}
\hline Disciplinas & Série I & Série II & Série III & Série IV \\
\hline LínGUAS & & & & \\
\hline Português & $\mathrm{X}$ & $\mathrm{X}$ & $\mathrm{X}$ & $\mathrm{X}$ \\
\hline Francês & $\mathrm{X}$ & $\mathrm{X}$ & - & - \\
\hline Inglês & $\mathrm{X}$ & $\mathrm{X}$ & $\mathrm{X}$ & $\mathrm{X}$ \\
\hline CIÊNCIAS & & & & \\
\hline Matemática & $\mathrm{X}$ & $\mathrm{X}$ & $\mathrm{X}$ & $\mathrm{X}$ \\
\hline Ciências & $\mathrm{X}$ & $\mathrm{X}$ & $\mathrm{X}$ & $\mathrm{X}$ \\
\hline História & $\mathrm{X}$ & $\mathrm{X}$ & $\mathrm{X}$ & $\mathrm{X}$ \\
\hline Geografia & $\mathrm{X}$ & $\mathrm{X}$ & $\mathrm{X}$ & $\mathrm{X}$ \\
\hline ARTES & & & & \\
\hline Trabalhos Manuais & $\mathrm{X}$ & $\mathrm{X}$ & - & - \\
\hline Desenho & - & - & $\mathrm{X}$ & $\mathrm{X}$ \\
\hline Canto Orfeônico & $\mathrm{X}$ & $\mathrm{X}$ & - & - \\
\hline Educação Artística & $\mathrm{X}$ & $\mathrm{X}$ & $\mathrm{X}$ & $\mathrm{X}$ \\
\hline
\end{tabular}

Fonte: MARQUES (2014, p. 86). 
Observamos que, no Curso Ginasial do Presidente Vargas, a disciplina de Latim, como humanidade clássica, foi igualmente tocada pela modificação iniciada pela LDB de 1961, sendo suprimida da grade curricular já no ano de 1962. As disciplinas de História e Geografia, que antes se configuravam divididas entre Geral e do Brasil, foram unidas, dessa maneira, passaram a constar na grade curricular apenas como História e Geografia. A disciplina de Ciências Naturais passou a ter apenas a denominação de Ciências.

Embora ocorressem essas modificações na grade curricular do Ginásio Presidente Vargas no ano de 1962, tal grade foi alterada nos moldes da Lei de Diretrizes e Bases da Educação Nacional - somente no ano de 1963, conforme se pode notar no Quadro 2:

Quadro 2 - Grade Curricular do Curso Ginasial do Ginásio Estadual Presidente Vargas de Dourados - 1963 a 1967

\begin{tabular}{|l|l|l|l|l|}
\hline Disciplinas & Série I & Série II & Série III & Série IV \\
\hline Português & $\mathrm{X}$ & $\mathrm{X}$ & $\mathrm{X}$ & $\mathrm{X}$ \\
\hline Matemática & $\mathrm{X}$ & $\mathrm{X}$ & $\mathrm{X}$ & $\mathrm{X}$ \\
\hline Inglês & - & - & $\mathrm{X}$ & $\mathrm{X}$ \\
\hline Ciências & $\mathrm{X}$ & $\mathrm{X}$ & $\mathrm{X}$ & $\mathrm{X}$ \\
\hline História do Brasil & $\mathrm{X}$ & $\mathrm{X}$ & - & - \\
\hline História Geral & - & $\mathrm{X}$ & $\mathrm{X}$ & $\mathrm{X}$ \\
\hline Desenho & $\mathrm{X}$ & - & $\mathrm{X}$ & $\mathrm{X}$ \\
\hline Francês & $\mathrm{X}$ & $\mathrm{X}$ & - & - \\
\hline Geografia & $\mathrm{X}$ & $\mathrm{X}$ & $\mathrm{X}$ & - \\
\hline Trabalhos Manuais & $\mathrm{X}$ & $\mathrm{X}$ & - & - \\
\hline Canto Orfeônico & $\mathrm{X}$ & $\mathrm{X}$ & $\mathrm{X}$ & $\mathrm{X}$ \\
\hline
\end{tabular}

Fonte: MARQUES (2014, p. 87).

O quadro apresentado revela que a grade curricular do Curso Ginasial passou a ter, a partir de 1963, apenas 10 disciplinas, ou seja, três a menos que as fixadas pela grade curricular anterior (1958 a 1961) e uma a menos que a configuração de 1962. Percebe-se que nessa grade a disciplina de Trabalhos Manuais já aparece suprimida. Em realidade, pode-se dizer que a implantação da Lei 4.024/61 fez com que algumas disciplinas praticamente desaparecessem dos currículos, por não terem sido escolhidas pelos estabelecimentos de ensino como optativas. No entendimento de Werebe (1970 
apud ZOTTI, 2004, p. 129-130), nesse currículo "a inovação de maior alcance foi a redução do número de matérias estudadas nos diversos cursos. Sem dúvida, as grades curriculares foram, de modo geral, muito aliviadas, limitando-se praticamente a exigir o mínimo indispensável para a formação cultural básica do aluno”.

A Lei de Diretrizes e Bases da Educação Nacional no 4.024/61 admitia, como matérias optativas, uma variedade de disciplinas curriculares, considerando as necessidades do local onde a escola estava inserida. Isso acaba por explicar, de certa forma, o fato de o Curso Ginasial do Presidente Vargas ter incluído nos anos de 1960, na composição de sua grade curricular, certas disciplinas optativas que se diferenciavam daquelas da grade curricular estabelecida em 1963, como se pode observar na grade de 1968:

Quadro 3 - Grade Curricular do Curso Ginasial do Ginásio Estadual Presidente Vargas de Dourados, 1968

\begin{tabular}{|l|l|l|l|l|}
\hline Disciplinas & Série I & Série II & Série III & Série IV \\
\hline Português & $\mathrm{X}$ & $\mathrm{X}$ & $\mathrm{X}$ & $\mathrm{X}$ \\
\hline Matemática & $\mathrm{X}$ & $\mathrm{X}$ & $\mathrm{X}$ & $\mathrm{X}$ \\
\hline Inglês & $\mathrm{X}$ & $\mathrm{X}$ & $\mathrm{X}$ & $\mathrm{X}$ \\
\hline Ciências & $\mathrm{X}$ & $\mathrm{X}$ & - & $\mathrm{X}$ \\
\hline História & $\mathrm{X}$ & $\mathrm{X}$ & $\mathrm{X}$ & $\mathrm{X}$ \\
\hline Desenho & - & - & $\mathrm{X}$ & $\mathrm{X}$ \\
\hline Ed. Moral e Cívica & - & - & - & $\mathrm{X}$ \\
\hline Organização Social Política Brasileira & & - & $\mathrm{X}$ & $\mathrm{X}$ \\
\hline Francês & - & - & $\mathrm{X}$ & $\mathrm{X}$ \\
\hline Geografia & - & $\mathrm{X}$ & $\mathrm{X}$ & $\mathrm{X}$ \\
\hline Educação Artística & - & - & $\mathrm{X}$ & - \\
\hline Téc. Manuais & - & - & $\mathrm{X}$ & - \\
\hline
\end{tabular}

Fonte: MARQUES (2014, p. 88).

Em 1968, como revela o quadro, a organização curricular do curso ginasial do Colégio Estadual Presidente Vargas passou por novas alterações, com a inclusão das disciplinas de Educação Moral e Cívica e Organização Social Política Brasileira. Pode-se dizer que a inclusão dessas duas disciplinas estava relacionada ao momento histórico que o Brasil atravessava, de regime militar, pois os governos militares enfatizavam o 
patriotismo e os "deveres cívicos" como forma de manutenção da ordem, aspectos que se faziam presentes nos conteúdos abordados de ambas as disciplinas.

Em 1971, a grade curricular do Curso Ginasial do Colégio permaneceu a mesma que fora estabelecida em 1968, com a inclusão das disciplinas "Educação Moral e Cívica" e "Organização Social Política Brasileira", como se pode observar no Quadro 4:

Quadro 4 - Grade Curricular do Curso Ginasial do Ginásio Estadual Presidente Vargas de Dourados em 1971

\begin{tabular}{|l|l|l|l|l|}
\hline Disciplinas & Série I & Série II & Série III & Série IV \\
\hline Português & $\mathrm{X}$ & $\mathrm{X}$ & $\mathrm{x}$ & $\mathrm{X}$ \\
\hline Matemática & $\mathrm{X}$ & $\mathrm{X}$ & $\mathrm{X}$ & $\mathrm{X}$ \\
\hline Inglês & $\mathrm{X}$ & $\mathrm{X}$ & $\mathrm{X}$ & $\mathrm{X}$ \\
\hline Ciências & $\mathrm{X}$ & $\mathrm{X}$ & - & $\mathrm{X}$ \\
\hline História & $\mathrm{X}$ & $\mathrm{X}$ & $\mathrm{X}$ & $\mathrm{X}$ \\
\hline Desenho & - & - & $\mathrm{X}$ & $\mathrm{X}$ \\
\hline Ed. Moral e Cívica & $\mathrm{X}$ & $\mathrm{X}$ & $\mathrm{X}$ & $\mathrm{X}$ \\
\hline Geografia & $\mathrm{X}$ & $\mathrm{X}$ & $\mathrm{X}$ & - \\
\hline Francês & - & - & $\mathrm{X}$ & $\mathrm{X}$ \\
\hline Geografia & $\mathrm{X}$ & $\mathrm{X}$ & $\mathrm{X}$ & \\
\hline Educação Artística & $\mathrm{X}$ & $\mathrm{X}$ & - & - \\
\hline Organização Social Política Brasileira & - & - & & $\mathrm{X}$ \\
\hline
\end{tabular}

Fonte: MARQUES (2014, p. 89).

Este quadro com a grade curricular do Curso Ginasial do Colégio Estadual Presidente Vargas permitiu observarmos, que no período de 1962 até o ano de 1974, ocorreram mudanças apenas na parte diversificada do currículo desse Curso. Contudo, as disciplinas que mais se revezavam na organização curricular, ora sendo acrescidas, ora excluídas, eram Artes, Trabalhos Manuais e Desenho. Entretanto, outras disciplinas foram acrescentadas no currículo, como no ano de 1972 a disciplina de Economia Doméstica, incluída pela primeira vez na parte diversificada 
da organização curricular do Curso Ginasial da instituição, conforme aparece no Quadro 5, a seguir:

Quadro 5 - Grade Curricular do Curso Ginasial da Escola Estadual Presidente Vargas de Dourados em 1972

\begin{tabular}{|l|l|l|l|l|}
\hline Disciplinas & Série I & Série II & Série III & Série IV \\
\hline Português & $\mathrm{X}$ & $\mathrm{X}$ & $\mathrm{X}$ & $\mathrm{X}$ \\
\hline Matemática & $\mathrm{X}$ & $\mathrm{X}$ & $\mathrm{X}$ & $\mathrm{X}$ \\
\hline Inglês & $\mathrm{X}$ & $\mathrm{X}$ & $\mathrm{X}$ & $\mathrm{X}$ \\
\hline Ciências & $\mathrm{X}$ & $\mathrm{X}$ & - & $\mathrm{X}$ \\
\hline História & $\mathrm{X}$ & $\mathrm{X}$ & $\mathrm{X}$ & $\mathrm{X}$ \\
\hline Desenho & - & - & $\mathrm{X}$ & $\mathrm{X}$ \\
\hline Ed. Moral e Cívica & - & - & - & $\mathrm{X}$ \\
\hline Geografia & $\mathrm{X}$ & $\mathrm{X}$ & $\mathrm{X}$ & - \\
\hline Francês & - & - & $\mathrm{X}$ & $\mathrm{X}$ \\
\hline Economia Doméstica & - & - & - & $\mathrm{X}$ \\
\hline Educação Artística & - & - & $\mathrm{X}$ & - \\
\hline Téc. Manuais & - & - & $\mathrm{X}$ & - \\
\hline
\end{tabular}

Fonte: MARQUES (2014, p. 89).

Embora já vigorasse em 1972, a Lei no 5.692/71, que fixou um núcleo comum obrigatório em todo o país e uma parte diversificada para atender as peculiaridades específicas de cada local, em Dourados, o Colégio Estadual Presidente Vargas optou pela disciplina de Economia Doméstica.

A disciplina de Economia Doméstica era ofertada na $4^{\text {a }}$ série do Curso Ginasial, somente para as mulheres. Por sua vez, os homens, no momento da ministração dessa disciplina, participavam das aulas de Educação Física. A disciplina "Economia Doméstica" fazia parte do currículo escolar ginasial como matéria optativa e tinha como finalidade formar a mulher para o lar e para a sociedade. Instruíam-se as mulheres para a atuação em suas funções como dona de casa, de acordo com o que seria, na época, o papel da mulher em seu contexto familiar. Isto é, uma "dona de casa" exemplar, uma esposa dedicada, cozinheira eficaz, mãe protetora, dentre outras funções que eram vistas como obrigações específicas para a pessoa do gênero feminino, ou seja, a mulher. 


\section{O caderno da disciplina de Economia Doméstica da ex-aluna do Curso Ginasial: práticas de formação e educação voltadas às mulheres}

A utilização de cadernos escolares como fontes oportuniza uma forma de aproximação para os estudos sobre as práticas da escola (GVIRTZ, 1997). No entendimento de Hébrard (2001, p. 121), o caderno "é o testemunho precioso do que pode ter sido e ainda é o trabalho escolar de escrita". Nesta mesma perspectiva, Mignot (2008, p. 13) aponta que o caderno é um "objeto quase invisível que guarda a memória da educação" que, a partir das indagações do pesquisador, é capaz de "falar" sobre alunos, professores, pais, projetos pedagógicos, avaliações, valores disseminados e todas as relações e práticas que circundam a escola.

No caso do caderno aqui analisado, referente à disciplina de Economia Doméstica, esse faz parte de um conjunto de documentos coletados e analisados em uma pesquisa sobre a história deste Colégio público, localizado em Dourados, no período de 1951 a 1974.

Em relação à localização deste caderno, durante a realização da pesquisa sobre a história desta instituição escolar, podemos reafirmar os dizeres de Mignot (2010): em decorrência da ausência de valorização e preservação de cadernos docentes e discentes, produzidos no âmbito escolar, os pesquisadores têm localizado esses materiais em arquivos pessoais, familiares, públicos e em museus pedagógicos. Assim, à semelhança disso, o Caderno da disciplina de Economia Doméstica aqui trabalhado foi localizado durante a pesquisa, guardado no arquivo pessoal da ex-aluna.

A escolha pela utilização do Caderno de uma ex-aluna do Curso Ginasial como fonte principal de pesquisa neste artigo se inscreve, principalmente, na esteira da investigação realizada pela pesquisadora argentina Gvirtz (1997), conforme abordado acima. A respeito da utilização de cadernos escolares como fontes de pesquisa, cabe destacar que tais fontes oportunizam uma forma de aproximação para os estudos sobre as práticas da escola. Na esteira disso, este artigo busca analisar, a partir desse Caderno da disciplina de Economia Doméstica, as práticas de formação e educação das mulheres nele tratadas em seus conteúdos. 
É certo que os cadernos, enquanto fontes privilegiadas para a pesquisa, constituem-se, por meio dos conteúdos a que se tem acesso, como uma pista, ou seja, são indícios do ocorrido em sala de aula, conforme apontam Santos (2002, 2008a, 2008b), Faria (1988), Oliveira (2008) e Viñao Frago (2008). Assim, não há como julgarmos, de acordo com Viñao Frago (2008), o contexto que envolvia as anotações no caderno, pois este era um espaço designado ao registro da produção escrita, de forma que o documento não apresenta o tempo destinado à produção para cada atividade, tampouco as intervenções orais e o vivido em sala de aula. Dessa maneira, “o máximo que podemos fazer é nos aproximarmos do passado e reconstruí-lo de modo parcial e com um enfoque determinado" (VIÑAO FRAGO, 2008, p. 25).

Com o objetivo de tomar o Caderno da disciplina de Economia Doméstica como fonte principal deste trabalho, a fim de analisar as práticas de formação e educação das mulheres nele contidas e tratadas em seus conteúdos, conforme os apontamentos de Viñao Frago (2008), buscamos fazer em torno desta fonte uma aproximação acerca do seu passado. Ao reconstruí-lo, mesmo que de forma parcial, propõe-se uma análise das práticas que estiveram presentes no fazer em sala de aula, voltadas somente para a formação e educação das mulheres, na disciplina Educação Doméstica no Curso Ginasial, no Colégio Estadual Presidente Vargas, no início da década de 1970.

Tal Caderno é de uma aluna que estudou na $4^{\mathrm{a}}$ série da turma A - período matutino, do curso Ginasial, em 1972, no Colégio Presidente Vargas, cuja turma era composta de 32 alunos: 18 do sexo masculino e 14 do sexo feminino.

Quanto às características do referido Caderno de Economia Doméstica, destacamos que se trata de um caderno do tipo brochura. Ele é de capa dura, de cor escura. Também cabe observar que é um material não encapado pela aluna e, além disso, percebe-se que contém folhas pautadas das quais quase todas estão com produções textuais escritas à caneta e com várias ilustrações. Nota-se que o objeto está bem conservado, ou seja, a capa e as 96 folhas não estão amassadas ou rasgadas.

Desde a primeira página, encontram-se ilustrações ou escritos à caneta, com letra bem legível e, ainda, com registros, principalmente, realizados na cor azul. $\mathrm{Na}$ página de abertura deste caderno, podemos observar a imagem de uma mulher - 
certamente, retirada de alguma revista que circulava no início dos anos de 1970 recortada e colada no caderno. Imagem essa de uma moça loira, com o cabelo arrumado, usando uma tiara de cor preta e uma vestimenta que parece modelada aos padrões do período, com luvas brancas nas mãos e segurando um ramalhete de rosas vermelhas. Ao mesmo tempo que a imagem colada no caderno permite entrever a representação de um perfil de uma moça feliz e séria, deixa perceber expressões de uma jovem meiga, como podemos observar por meio da Figura 1.

Figura 1 - Cópia da abertura do caderno de economia doméstica da ex-aluna de 1972

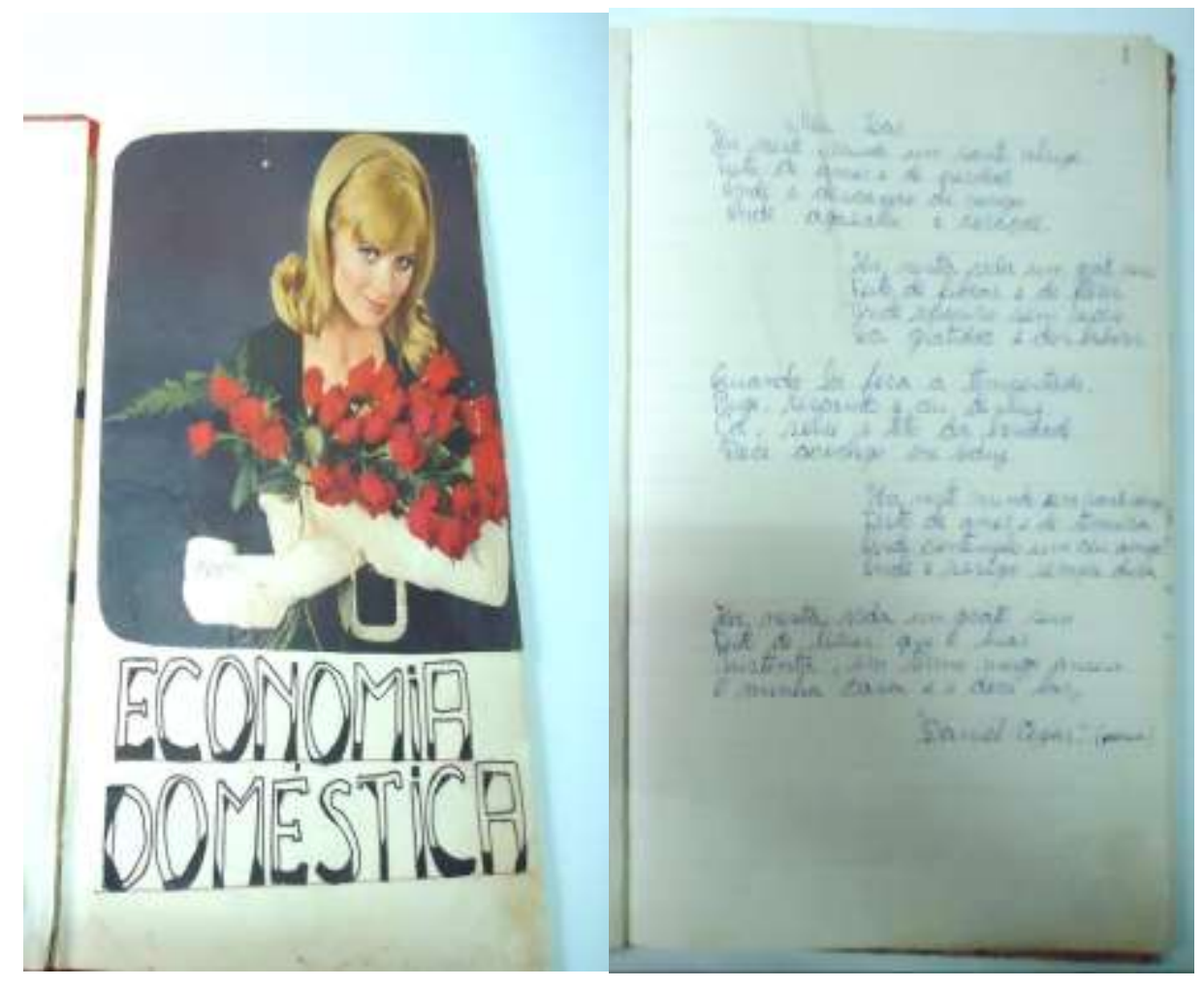

Fonte: ARQUIVO PESSOAL DE EX-ALUNA.

A partir desta imagem da primeira página, juntamente com outras, podemos notar que a aluna tinha uma forte preocupação com a organização estética do seu Caderno de Economia Doméstica, uma vez que a maioria das folhas aparece com os conteúdos da disciplina registrados com ilustrações coladas, representativas do tema abordado na aula. Ilustrações as quais, possivelmente, foram retiradas e recortadas pela própria aluna de revistas, livros e jornais. A esse respeito, Viñao Frago (2008, p. 
23) aponta que “o 'efeito estético' tem também um sentido ético, regularizador e disciplinar". Com todo esse "efeito estético", podemos afirmar que essa aluna da $4^{\text {a }}$ série da turma A do Curso Ginasial de 1972, do Colégio Estadual Presidente Vargas, localizado na cidade de Dourados, procurava organizar os conteúdos de suas aulas de Economia Doméstica - fato este evidenciado pelas ilustrações contidas no Caderno.

Outro aspecto significativo presente na abertura do caderno, logo ao lado da ilustração referente à imagem da moça loira, vem escrito uma poesia intitulada "Meu lar", como podemos observar na transcrição desta poesia abaixo, feita a partir deste caderno:

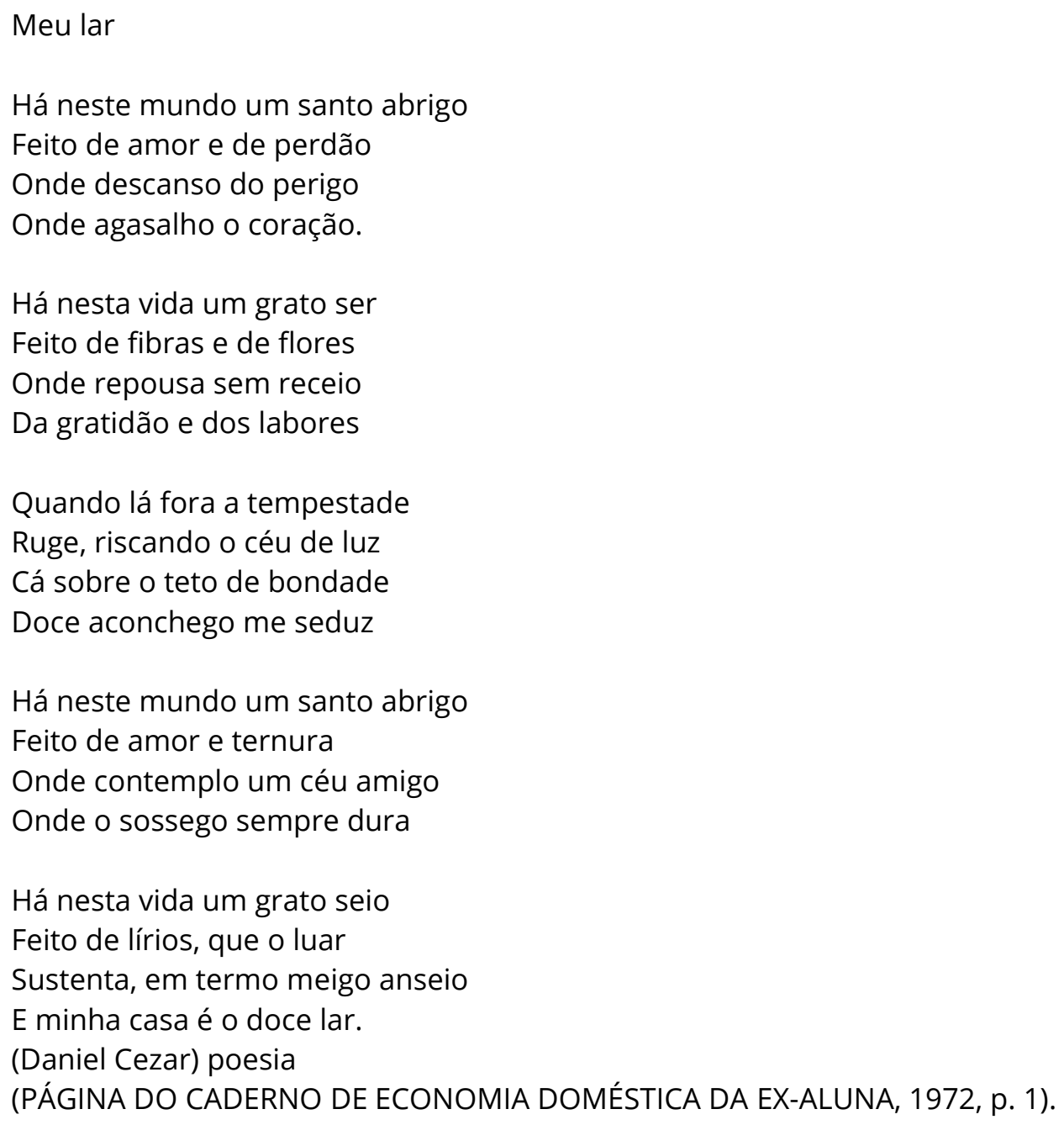

Embora não seja possível saber ao certo se foi a aluna que pesquisou esta poesia e escreveu no caderno ou se foi a professora que passou esta poesia durante a aula de Economia Doméstica, conforme mencionou Viñao Frago (2008), por meio da análise dos cadernos enquanto fontes de pesquisa, é possível fazermos aproximações acerca do seu passado e reconstruí-lo, de modo parcial. No entanto, 
não podemos negar que esta poesia tinha e tem um objetivo de valorização da importância de um lar para as jovens moças do Curso Ginasial, uma vez que o termo lar, na poesia, chega a ser tratado como um santo abrigo, um lugar de proteção das tempestades de fora, um espaço feito de amor, ternura, sossego, constituindo-se, assim, uma casa como um doce lar, a exemplo de como o poeta Daniel Cezar finaliza a sua poesia.

Ainda que as mulheres, por meio de suas inúmeras reivindicações, tenham alterado a situação ao longo do tempo, recriando e lutando contra o discurso que as reduzia ao lar, ao casamento e à maternidade, buscando impor-se ao mundo e ganhar seu espaço na vida pública, conforme apontam os estudos de Del Priore (1997), Perrot (1998), Almeida (2004), observamos que, em relação aos conteúdos da disciplina de Economia Doméstica estudados pela aluna do Curso Ginasial e registrados em seu caderno, ainda no início dos anos de 1970, são conteúdos que visavam formar as mulheres como uma "boa dona casa" e "mãe de família". Tais conteúdos versavam sobre organização do lar, como cozinhar, organizar a cozinha, lavar roupa, lavar e secar louça, a conservação de alimentos, livros de receitas, contabilidade doméstica, cuidados com o recém-nascido e a criança pequena, cuidados higiênicos, noções de enfermagem, limpeza e organização de casa, decoração de sala, organização do guarda-roupa, enfim, tudo o que estava relacionado com a vida cotidiana da "dona de casa".

Não podemos deixar de registrar aqui que na história das mulheres e, mais precisamente, na história da educação das mulheres, este tipo de educação proporcionava às jovens do sexo feminino uma formação para "[...] um sólido ambiente familiar, lar acolhedor, filhos educados e a esposa dedicada ao marido e sua companheira na vida social são considerados um verdadeiro tesouro [...]” (DEL PRIORE, 1997, p. 223), situação essa que perdurou por muitas décadas e marcou a geração, a formação e a educação de muitas mulheres.

Todavia, os conteúdos encontrados no caderno da ex-aluna nos permitem problematizar a instituição escolar de origem e o seu cotidiano, pois os cadernos como objetos da cultura escolar podem ser entendidos para além de sua materialidade, uma vez que neles estão escritos conteúdos nas suas linhas e 
entrelinhas e, justamente neste ponto, caberiam alguns questionamentos, que podem ser desdobrados da nossa problemática inicial e contribuir para as análises aqui empreendidas. Sendo assim, cumpre interrogar: por que o Colégio Estadual Presidente Vargas, de Dourados, optou por inserir entre as suas disciplinas a disciplina optativa de Economia Doméstica para as alunas da 4a série do Curso Ginasial e não outra? Haveria alguma relação da inserção desta disciplina no currículo com o contexto histórico do período civil-militar vivenciado no Brasil, nesta época?

É certo que a década de 1960, no Brasil, foi marcada pelo início da ditadura militar, que se estendeu por toda a década de 1970, e só perdeu a sua força no início dos anos 1980, com os primeiros passos rumo à abertura proposta pelo governo Geisel, mediante a revogação do Ato Institucional n ${ }^{\circ} 5$ e pelo movimento em prol da anistia.

No entanto, parece que o interesse por esta disciplina optativa de Educação Doméstica, no Colégio Estadual Presidente Vargas, cujo caderno escolar de uma aluna egressa é tomado como fonte principal de pesquisa neste artigo, no início da década de 1970, tem relação direta com o período civil-militar vivenciado nesta mesma época, no país. Conforme esclarece Pinto (2003), nesse período, no Brasil, convivia-se com o conservadorismo da sociedade.

No que diz respeito à educação, Oliveira e Souza (2012) apontam que o regime militar utilizava a educação para atingir seus objetivos, ou seja, instruindo-se a partir da ideia de que "todos" poderiam gozar das "benesses" que o “desenvolvimento" poderia proporcionar, inibindo a construção de qualquer outra forma de organização social diferente daquela difundida pelos militares. A esse respeito, não podemos esquecer também das advertências de Viñao Frago (2008) sobre os cadernos escolares, pois é importante compreender que esses também silenciam certos registros.

Outro texto escrito presente no caderno da ex-aluna que merece ser analisado é um cabeçalho intitulado "Organização do guarda-roupa":

\section{Cabeçalho: Organização do guarda-roupa}


O guarda-roupa deverá ser organizado de acordo com as divisões, sendo que uma parte deverá ser para o homem e outra para a mulher. Nos cabides, as roupas devem ser penduradas por seqüencia (Sic.) de cores e ainda por ordem de prioridade. Nas gavetas, deverá haver uma organização em que as calcinhas e sutiãs sejam dispostos de uma maneira acessível, e da mesma maneira as cuecas e os pijamas.

Os lençóis e toalhas devem ser colocados em partes separadas. Os cobertores guardados em sacos, nas partes que não atrapalham o dia a dia. Uma limpeza no guarda-roupa deve feita a cada 30 dias juntamente com a organização das roupas dentro dele.

Quando for feita esta limpeza e organização deve-se tirar toda a roupa, passar um pano com amoníaco, aguardar alguns segundos e, em seguida dispor novamente todas as roupas dentro do armário, tendo o cuidado de separar as roupas que não servem para reformar e ou doar.

(PÁGINA DO CADERNO DE ECONOMIA DOMÉSTICA DA EX-ALUNA, 1972, p. 19)

Nesse tipo de escrita, possivelmente, o professor da disciplina escrevia o texto e as alunas apenas copiavam da lousa. Todavia, neste texto, é possível entrever uma situação bem comum vivenciada pelas donas de casa em seu cotidiano em família, pois ele perpassa procedimentos de passo a passo de como organizar um guarda-roupa, dimensionando a parte que deveria ser destinada ao homem e à mulher, bem como uma sequência de como deveria ser guardado cada tipo de roupa. Inclusive, ensinava-se até sobre a limpeza desse móvel e os cuidados que se deveria ter com as roupas que não eram mais usadas.

De um modo geral, podemos perceber que um texto como este buscava trazer informações de forma detalhada às jovens moças do Colégio sobre uma atividade presente no universo da mulher, como dona de casa e mãe de família. Com isso, visava prepará-las como mulheres prendadas e boas donas de casa.

Há ainda outros tantos conteúdos registrados no Caderno de Economia Doméstica relacionados ao fazer cotidiano da dona de casa, com abordagens sobre limpeza de casa, limpeza de objetos de couro e de borracha, ornamentação da casa, explicações sobre os talheres, a respeito do banheiro - inclusive com explicações acerca do tamanho deste cômodo na casa -, economia, entre outros.

Ademais, há de se registrar aqui também o conteúdo intitulado "economia doméstica", que dava indícios de uma formação e educação para as mulheres, o 
qual, podemos dizer, estava baseado na administração da casa, conforme observamos no fragmento:

A necessidade da economia doméstica e os estudos que comporta Economia é empregar utilmente o que se possui ou o que se vinha a adquirir ou se juntar, guardar não basta. Há poupança exagerada e sem objetivos lógicos com prejuízo dos aspectos da vida seus piores aos bens materiais, não é economia. A economia deve constituir um abito e ter que ser feito e terá que ser feito com inteligência, pois somente assim proporcionará ao indivíduo e a sociedade, familiar a independência e a capacidade de auxiliar ao próximo. É a base da riqueza uma das condições para a felicidade. Para viver o indivíduo e sua família necessitam de certo número de bens. O estudo das necessidades da família dos bens que constituem o seu patriotismo é a forma de administração desses bens, são o objetivo da família, e da economia doméstica. Economia doméstica significa administrar uma casa, de modo a obter o máximo de aproveitamento dos bens adquiridos, com o mínimo de gastos. Há diferenças de ciências domesticas e economia domésticas. A ciência doméstica abrange todos os problemas relativos a direção geral do lar, restringindo-se no campo de economia doméstica e provas do trato dos bens materiais.

(PÁGINA DO CADERNO DE ECONOMIA DOMÉSTICA DA EX-ALUNA, 1972, p. 2).

Aqui é possível inferir que a disciplina de Economia Doméstica, por meio de seus conteúdos, buscava a formação e a educação de mulheres, para além do que foi marcada a história das mulheres e da sua educação, em determinados períodos da nossa história, conforme evidenciam alguns estudos de Del Priore (1997), Perrot (1998), Almeida (2004), entre outros, uma vez que os seus conteúdos visavam formar além de donas de casa, mulheres prendadas em seus afazeres domésticos: boas mães de família, mulheres que fossem também boas administradoras de suas casas, no que diz respeito aos bens materiais e financeiros.

Diante desses aspectos vinculados à disciplina de Economia Doméstica presentes nos conteúdos do caderno da ex-aluna do Curso Ginasial do Colégio Estadual Presidente Vargas de Dourados, podemos reafirmar os apontamentos de Souza (2008, p. 180) de que “a escolarização de saberes práticos, próprios do universo feminino, exemplifica, com propriedade, como a seleção de conteúdos para o currículo escolar tende, muitas vezes, a dar uma resposta aos problemas sociais", pois compreendemos que principalmente os conteúdos de Economia Doméstica direcionados à mulher, visando à formação de uma administradora da casa, acabam por colocar em prática neste processo a formação educacional das mulheres, saberes práticos e próprios do universo feminino, conforme registra Souza (2008), com o 
intuito de que sirvam para resolver problemas vivenciados socialmente pelas donas de casa, na tarefa de administrar uma família e um lar.

Assim, o Caderno de Economia Doméstica da ex-aluna se tornou uma fonte de pesquisa importante para compreensão de parte do processo de escolarização, ocorrido no Curso Ginasial do Colégio Estadual Presidente Vargas, no início dos anos de 1970, por registrar conteúdos e procedimentos de ensino de uma disciplina tida na composição curricular deste curso como optativa e direcionada exclusivamente às mulheres, em um determinado momento histórico e social na instituição escolar em Dourados, interior de Mato Grosso.

\section{Considerações finais}

Um artigo desta natureza nos permitiu compreender e refletir sobre os processos educativos, ao tomar um caderno escolar como fonte principal de pesquisa, a fim de se analisar a forma como era ensinada a disciplina optativa de Educação Doméstica para as jovens moças, em um Curso Ginasial de uma instituição escolar situada no interior do antigo Mato Grosso, mais especificamente, o Colégio Estadual Presidente Vargas, localizado na cidade de Dourados, no início dos anos de 1970. Assim, podemos dizer que os cadernos escolares, enquanto fontes privilegiadas para pesquisa, constituem-se como indícios, pistas e vestígios do ocorrido em sala de aula.

Neste contexto, podemos afirmar que o Caderno de Educação Doméstica utilizado nesta pesquisa se constituiu em uma fonte importante para a compreensão do ensino de uma disciplina voltada, essencialmente, às jovens moças do Curso Ginasial, mais precisamente, para a turma da $4^{\text {a }}$ série, desse tempo e lugar. O caderno da ex-aluna do Curso Ginasial possibilitou, como uma fonte documental, entrever parte do processo de ensino da disciplina de Economia Doméstica, bem como compreender os conteúdos trabalhados e desenvolvidos para a formação e a educação das mulheres moradoras do interior do estado de Mato Grosso, situado na região Centro-Oeste do Brasil. 
Ainda por meio deste Caderno de Economia Doméstica, foi possível perceber a presença de práticas de formação e educação das mulheres, ainda nos anos de 1970, presentes em seus conteúdos que visavam à formação e à educação dessas jovens moças como boas donas de casa, mulheres prendadas em seus afazeres domésticos, boas mães de família e boas administradoras de suas casas.

\section{Referências}

ALMEIDA, J. S. A. Mulheres na educação: missão, vocação e destino? A feminização do magistério ao longo do século XX. In: SAVIANI, D. et al. O legado educacional do século XX no Brasil. Campinas: Autores Associados, 2004. p. 59-94.

BRASIL. Lei no 4.024, de 20 de dezembro de 1961. Fixa as Diretrizes e Bases da Educação Nacional. Disponível em: http://www.mec.gov.br/. Acesso em: 10 ago. 2020.

DEL PRIORE, M. História das mulheres no Brasil. São Paulo: Contexto, 1997.

FARIA, V. L. B. No caderno da criança o retrato da escola. 1988. 258f. Dissertação (Mestrado em Educação) — Universidade Federal de Minas Gerais, Belo Horizonte, 1988.

GOODSON, I. F. A construção social do currículo. Lisboa: Educa, 1997.

GOODSON, I. F. Currículo: Teoria e História. Petrópolis, RJ: Vozes, 1995.

GVIRTZ, S; LARRONDO, M. Os cadernos de classe como fonte primária de pesquisa: alcances e limites teóricos e metodológicos para sua abordagem. In: MIGNOT, A. C. V. (org.). Cadernos à vista: escola, memória e cultura escrita. Rio de Janeiro: EdUERJ, 2008. p. 35-48.

GVIRTZ, S. Del curriculum prescrito al curriculum enseñado: uma mirada a los cuadernos de clase. Buenos Aires: Aique, 1997.

HÉBRARD, J. Por uma bibliografia material das escritas ordinárias: o espaço gráfico do caderno escolar (França - séculos XIX e XX). Trad. Laura Hansen. Revista Brasileira de História da Educação, Campinas, n. 1, p. 115-141, jan./jun. 2001.

JORNAL O PROGRESSO. Dourados, 1958.

LOPES, E. M. T.; GALVÃO, A. M. O. História da educaşão. Rio de Janeiro: DP\&A, 2001

MARQUES, I. V. O Ensino Secundário no Sul de Mato Grosso: o Colégio Estadual Presidente Vargas de Dourados (1951-1974). 2014. 134f. Dissertação (Mestrado em Educação) Faculdade de Educação, Universidade Federal da Grande Dourados, Dourados, 2014.

MIGNOT, A. C. V. Janelas indiscretas: os cadernos escolares na historiografia da educação. In: VIDAL, D. G.; SCHWARTZ, C. M. História das culturas escolares no Brasil. Vitória: EDUFES, 2010. 
MIGNOT, A. C. V. Um objeto quase invisível. In: MIGNOT, A. C. V. Cadernos à vista: Escola, Memória e Cultura escrita. Rio de Janeiro: EdUERJ, 2008.

OLIVEIRA, I. B. Aprendendo com os cadernos escolares: sujeitos, subjetividades e práticas sociais cotidianas na escola. In: MIGNOT, A. C. V. Cadernos à vista: escola, memória e cultura escrita. Rio de Janeiro: EdUERJ, 2008.

OLIVEIRA, L. B.; SOUZA, S. T. A alfabetização no Mobral, métodos e materiais didáticos (Uberlândia/MG, 1970-1985). Acolhendo a Alfabetização nos Países de Lingua Portuguesa, v. 7, n. 13, 2012.

PERROT, M. Mulheres públicas. São Paulo: EdUNESP, 1998.

PINTO, C. R. J. Uma história do feminismo no Brasil. São Paulo: Fundação Perseu Abramo, 2003.

SANTOS, A. A. C. Aprendendo a usar cadernos: um caminho necessário para a inserção na cultura escolar. In: MIGNOT, A. C. V. Cadernos à vista: Escola, Memória e Cultura escrita. Rio de Janeiro: EdUERJ, 2008a.

SANTOS, A. A. C. Cadernos e outros registros escolares da primeira etapa do ensino fundamental: um olhar da psicologia escolar crítica. 2008. 331f. Tese (Doutorado em Psicologia) Universidade de São Paulo, São Paulo, 2008b.

SANTOS, V. M. O nascimento dos cadernos escolares: um dispositivo de muitas faces. 2002. 134f. Dissertação (Mestrado em Educação e Cultura) - Universidade do Estado de Santa Catarina, Florianópolis, 2002.

SILVA, Geraldo Bastos. A educação secundária: perspectiva histórica e teoria. São Paulo: Nacional, 1957. 416 p. (Atualidades Pedagógicas, v. 94)

SOUZA, R. F. História da Organização do Trabalho escolar e do Currículo no século XX: (ensino primário e secundário no Brasil). v. 2. São Paulo: Cortez, 2008.

VIÑAO FRAGO, A. Os Cadernos escolares como fonte histórica: aspectos metodológicos e historiográficos. In: MIGNOT, A. C. V. Cadernos a vista: Escola, Memória e Cultura escrita. Rio de Janeiro: EdUERJ, 2008.

ZOTTI, S. A. Sociedade, educação e currículo no Brasil: dos jesuítas aos anos de 1980. São Paulo: Autores Associados, 2004.

RECEBIDO: $31 / 08 / 2020$

APROVADO: 07/10/2020

RECEIVED: 08/31/2020

APPROVED: $10 / 07 / 2020$

RECIBIDO: $31 / 08 / 2020$

APROBADO: 07/10/2020 